\title{
Hardseededness and the accuracy of seed bank estimates obtained through germination
}

\author{
J. E. Malo
}

Malo, J. E. 2000. Hardseededness and the accuracy of seed bank estimates obtained through germination. - Web Ecol. 1: 70-75.

\begin{abstract}
The seed content of soils is often estimated through germination tests, though these methods are always somewhat inaccurate due to the presence of dormant seeds in the samples. The researcher thus faces the question of whether to continue the germination test or to stop it in the search for an accuracy-to-effort balance. In this paper I analyze the accuracy of seed content estimates obtained after a first-year germination test, by comparison to the germination recorded after three-year cultivation, in 48 soil seed bank samples and 389 from herbivore dung. After the first 9-month cultivation, I recorded $85 \pm 1 \%$ seedlings and $90 \pm 1 \%$ species in soil samples, while the accuracy in those of dung was significantly lower, $48 \pm 1 \%$ seedlings and $65 \pm 1 \%$ species. The accuracy of estimations varied among samples within experiments, with significant differences in the estimation of species richness in both cases. I did not find consistent differences in the accuracy of estimations linked to seedling densities in growing pots, but the taxonomic composition of samples was a major source of bias. Thus, $22 \%$ and $36 \%$ of the most frequent species showed germinabilities in the first year significantly different from the rest, and some generalities arose, like the high germinability of grasses and the hardseededness of legumes. I would thus recommend the use of at least two germination cycles for seed bank estimations and a cautious approach when comparing samples with very different origin and/or taxonomic composition.
\end{abstract}

J.E. Malo (je.malo@uam.es), Facultad de Ciencias, Universidad Autónoma de Madrid, E-
28049 Madrid, Spain.

The knowledge of the seed content of samples, mainly from soil, is a relevant question in ecology and one of increasing interest (Thompson, K. 1992). The estimation of the seed content of samples is carried out by seed sorting prior to identification and counting, or by cultivation and seedling control (Ball and Miller 1989, Forcella 1992). Seed bank analysis is often estimated through germination when samples have many seeds and are species-rich, as well as when only viable seeds are the targets of study. In such circumstances, seed sorting methods are tedious and must be complemented with viability tests.

The main drawbacks of germination tests are the inac- curacy of the results due to their inability to detect a fraction of dormant seeds. Such errors may be considered as sampling inaccuracies if $<5 \%$ (a standard for scientific trustworthiness) and if no consistent biases exist among sample groups, but they are of concern otherwise. Thus, major concerns come from differences in germinability among samples of any experiment, as they lead to biased comparisons due to differences in detectability among sampling individuals (Thompson S. K. 1992). Therefore, germination tests raise the question of when to stop cultivation, since some dormant seeds may always pass undetected. 
The three main reasons for concern are due to differences in dormancy linked to the 1) seed densities and 2) taxonomic composition of samples, or 3) to characteristics of individual samples. On the one hand, overcrowding of seedlings may prevent further germination (Harper 1977), thus reducing the observed differences in the seed content of samples with high and low seed densities. On the other hand, differences in germinability among species lead to the underestimation of highly dormant taxa (Russi et al. 1992a, Thanos et al. 1992) and to biases in the comparison of samples due to their taxonomic composition. Finally, the origin of the seeds present in any sample, and the environmental conditions to which they had been subjected, can modify their germinability (Meyer and Monsen 1992, Bewley and Black 1994) and also generate biased comparisons.

My objectives in the present paper are thus: 1) to test if data obtained after one-year cultivation in glasshouse are essentially similar to those obtained after three such growth cycles, and 2) to analyze biases in the one-year data due to differences among samples, with special attention to taxonomic bias in seed bank estimations.

\section{Methods}

Data used in this analysis come from two experiments carried out in a pastoral system in central Spain: an estimation of soil seed banks and a study of seed content in herbivore dung. The former was composed of 48 soil samples of $10 \times$ $10 \mathrm{~cm}$ in which seed bank build-up in one year was analyzed as a function of two factors, slope position (high, medium and low) and seed input in herbivore dung (control vs dung removal). Seed bank build-up was measured through the replacement in winter of the uppermost 10 $\mathrm{cm}$ of soil with seed-free arkose, and the collection of soil samples in autumn for seed germination. The arkose used for the soil replacement had the same texture as the replaced soil and it was tested for the absence of germinable seeds by cultivation of $400 \mathrm{~g}$ together with the rest of samples (see detailed field methods in Malo et al. 1995). The second experiment analyzed the seasonal seed content of dung from rabbit, fallow deer, red deer and cattle with a total of 416 samples. Rabbit and fallow deer samples had 3 $\mathrm{g}$ dry weight, and those of red deer and cattle $6 \mathrm{~g}$, and they were respectively mixed with 25 or $50 \mathrm{~g}$ seed-free soil prior to cultivation in one or two pots (methods in Malo and Suárez 1995, though in that analysis 3-g (sub-) samples were used for all animal species).

In both cases I collected the samples in 1990, placed them in similar pots, and subjected them to three October-July growth cycles (1990-91, 1991-92 and 1992-93) in the same glasshouse. I laid samples in thin layers (1.5-2 $\mathrm{cm}$ ) on a piece of gauze on a bed of vermiculite and I kept them constantly moist. During the growth cycles, I uprooted and registered the seedlings once their development permitted identification, and I often stirred the soil to enhance germination. This procedure is basically similar to those commonly used in seed bank estimation through germination (Ball and Miller 1989, Forcella 1992).

I have carried out all analyses by comparing the results I got after the first growth cycle to those obtained from the addition of all three. Thus "estimation accuracy" henceforth denotes the percentage of seeds (or species) sprouted from any sample in the first year with respect to its 3-yr total.

Due to the percentage nature of data I have used angular transformations for parametric analyses, while I have applied non-parametric tests to the raw data when the violation of assumptions could lead to misleading conclusions from them (Zar 1996). I have tested if there are differences in estimation accuracy for seed density and species richness between experiments, and among sample types and seed densities within them. I have also analyzed the differences in the estimation accuracy of seed densities individually for the most frequent species (present in $>5$ soil or 9 dung samples) to detect species with estimation accuracies significatively higher or lower than the rest. In this case I have used Mann-Whitney U tests followed by the Bonferroni sequential probability correction of probabilities to avoid the problem of multiple inferences (Rice 1989), with a significance threshold of $\mathrm{p}<0.05$.

\section{Results}

\section{Biases within and among experiments}

A total of 7049 seeds sprouted from the 48 soil samples, 5896 of them during the first growth cycle, 823 the second and 330 the third. The estimation accuracy after the first year was $85.0 \pm 1.1 \%$ (mean $\pm \mathrm{SE}$ ), with no significant differences among sample types, slope positions, neither associated with the interaction of both (ANCOVA test, $\mathrm{N}$ $=48, \mathrm{p}>0.05$; Table 1 and Fig. 1). Though the percentage of sprouted seeds was somewhat lower among samples with more seeds $(B=-0.089)$, the relation is far from significant (Table 1).

I found 70 species in soil samples, 65 of which appeared in the first year and the last 5 in the second. The estimation accuracy for species richness of samples was $89.6 \pm 1.0 \%$, though I found it to be significantly higher for dung removal samples $(92.1 \pm 1.3 \%)$ than for control ones $(87.1 \pm$ 1.5\%; ANCOVA test, $\mathrm{N}=48, \mathrm{p}<0.05$; Table 1 and Fig. $1)$. All other factors as well as the covariate seedling density $(B=-0.113)$ were non-significant (Table 1$)$.

After three years, 17651 seedlings sprouted from the 389 dung samples that had any seeds, but only 9491 seeds did so in the first year. I obtained a $47.7 \pm 1.4 \%$ germination in the first year, with no significant differences among samples belonging to the four herbivores (Kruskal-Wallis $\mathrm{H}=7.14 ; \mathrm{N}=389 ; \mathrm{p}=0.068$ ), though it was somewhat 
Table 1. Summary of ANCOVA results for the relationship of the accuracy of seed density and species richness estimation in the soil seed bank samples after one-year germination with the factors treatment (control vs dung removal), position on the slope (high, medium and low) and their interaction, and with the covariate number of seeds in the sample.

\begin{tabular}{lccc}
\hline Effects & DF & F & p \\
\hline Accuracy of seed density estimation & & & 0.618 \\
$\quad$ Treatment & 1 & 0.252 & 0.124 \\
Position on the slope & 2 & 2.201 & 0.441 \\
Treatment $\times$ position & 2 & 0.441 & 0.571 \\
Number of seeds in the sample & 1 & 0.326 & 0.030 \\
Error & 41 & & 0.552 \\
& & & 0.887 \\
Accuracy of species richness estimation & 1 & 5.032 & 0.470 \\
Treatment & 2 & 0.603 & 0.121 \\
Position on the slope & 2 & 0.531 & \\
Treatment $\times$ position & 1 & & \\
Number of seeds in the sample & 41 & & \\
Error & & & \\
\end{tabular}

higher for cattle $(52.7 \pm 2.2 \%)$ and rabbit samples $(48.7 \pm$ $1.6 \%)$, than for those of fallow $(45.1 \pm 1.6 \%)$ and red deer $(44.6 \pm 3.7 \%)$. However, I found significant differences among herbivores in the relationship between seedling density of samples and their percentage of germination in the first growth cycle (Parallelism test, $\mathrm{F}=7.87 ; 3 \mathrm{DF} ; \mathrm{p}<$ $0.001)$. Thus, such relationships are positive among red deer dung samples (Pearson $\mathrm{r}=0.344 ; \mathrm{n}=91 ; \mathrm{p}<0.001$ ) and negative among those of rabbit $(r=-0.317 ; n=101 ; p$ $=0.001$ ), though no differences in seedling densities could be blamed for that.

In dung samples, I recorded a total of 107 species, with an estimation accuracy for sample species richness of 64.8 $\pm 1.4 \%$. The accuracy of estimations was significantly different among sample types (ANCOVA test, $\mathrm{N}=389 ; \mathrm{p}<$ 0.05 ; Table 2), with values of $63.6 \pm 2.6 \%$ in rabbit dung samples, $71.3 \pm 2.4 \%$ in fallow deer's, $52.7 \pm 2.2 \%$ in red deer's and $70.6 \pm 2.3 \%$ in those of cattle. Moreover, I found the estimation accuracy to be significantly higher for samples with more seedlings $(~(B=0.168$; Table 2$)$.
Finally, I found highly significant differences between experiments in the estimation accuracy of the number of seeds (ANOVA test, $\mathrm{F}=67.5 ; 1 \mathrm{DF} ; \mathrm{p}<0.001$ ) and the species richness of samples $(F=25.5 ; 1$ DF; $p<0.001)$. In both cases, the accuracy of estimations was much lower for dung samples.

\section{Taxonomic biases}

I found significant differences among the most frequent species in the proportion of seeds sprouted in the first year (Table 3). The estimation accuracy for 6 out of the 37 most frequent species in soil samples was significantly lower than for the rest (U-test, $\mathrm{p}<0.05$ after the probability correction of Rice 1989), and 2 species showed the reverse pattern. Grasses and species in the Caryophyllaceae showed in general rapid germinability, contrary to the hardseededness of legumes. Species from other families like composites and crucifers had high as well as low first-year germinabilities.
Fig 1. Percentage of seeds a) and species b) by treatments (stripped: control, empty: dung removal) and slope positions detected during the first year cultivation of soil samples. In all cases $\mathrm{n}=8$. Comparison tests in Tables 1 and 2 . a)

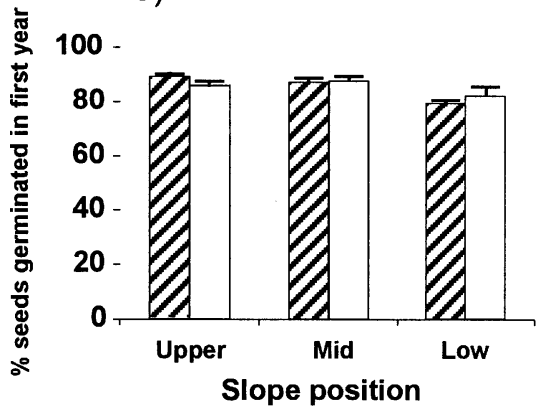

b)

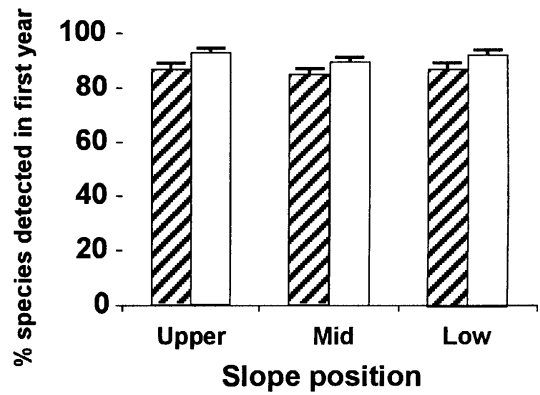


Table 2. Summary of ANCOVA results for the relationship of the accuracy of the seed density estimation of dung samples obtained after one-year cultivation with the factor dung type and the covariate number of seeds in the sample.

\begin{tabular}{lrrr}
\hline Effects & DF & F & p \\
\hline Dung type & 3 & 8.602 & $<0.001$ \\
Number of seeds in the sample & 1 & 11.203 & $<0.001$ \\
Error & 384 & & \\
\hline
\end{tabular}

Among the 47 most frequent species in dung samples, I detected 9 species with a significantly higher germinability and 8 with a lower one. Grasses again are notable for the high accuracy of their estimation with a one-year cultivation of samples (significantly higher in all 6 species) and the Caryoplyllaceae by the contrary (lower in 4 out of 8 species). Most crucifers and legumes had also low first-year germinabilities, though Biserrula pelecinus L. showed a significantly high one among the last.

\section{Discussion}

The results show that germination tests based on one growth-cycle cultivation can lead to rather inaccurate estimation of seed banks, and that the magnitude of such inaccuracies varies notably among samples and experiments. Moreover, differences in the quality of estimations can arise among samples due to their taxonomic composition. The method used did not allow for a complete seedbank estimation, but since only $5-15 \%$ of seedlings sprouted during the third growth-cycle these results can be considered a consistent, or conservative at worst, estimation of possible inaccuracies.

The accuracy of estimations that I have found is almost always below $90 \%$, well under the usual thresholds for scientific trustworthiness. It would be thus inadvisable to proceed on the statistical analyses of results searching for differences among samples with probability thresholds of $\mathrm{p}$ $<0.05$ or lower after the first growth cycle, provided that the original data had not been taken with that precision (Zar 1996). Even an estimation accuracy between 95$100 \%$ could be of concern for total seed bank estimation and for comparison purposes, though it could be treated like sampling error provided that such error was not biased among species or samples.

The samples I have used in the analysis, soil seed bank build-up in one year and herbivore dung, are not exact representatives of the most common study subject, soil seed banks, and the extrapolation of the results to them should be thus cautious. Seed bank build-up comprises only freshly produced seeds, which can show a lower as well as a higher germinability than the normal seed pool of soil. On the one hand, recently produced seeds may need a maturation period prior to germination (Bewley and Black 1994), thus leading to a decrease of estimation accuracy as I have calculated them. However, seeds were not directly taken from the plant but from the soil at the end of the summer, and they were thus subjected to the dehydration and the daily heating-cooling cycles of summer. Since both processes play a key role in seed maturation (Baskin and Baskin 1989, Bewley and Black 1994) and are the normal conditions faced by seeds in Mediterranean climates, there is no reason to suspect abnormally high levels of dormancy among them. On the other hand, the samples did not contain the fraction of seeds that persist in the soil over years

Table 3. Taxonomic differences in the percentage of first-year germination among the most common species in soil and dung samples ${ }^{1}$. Data presented in the table are the number of species in each plant family $(\mathrm{N})$, the mean $(\%)$ and range of percentage of first-year germination among them, and the number of species for which it is significatively higher or lower than the mean (signif; $\mathrm{H}$, high; L, low; U-test $\mathrm{p}<0.05$ after probability correction, see text).

\begin{tabular}{|c|c|c|c|c|c|c|c|c|}
\hline \multirow[b]{2}{*}{ Plant family } & \multirow[b]{2}{*}{$\mathrm{N}$} & \multicolumn{3}{|c|}{ Soil samples } & \multirow[b]{2}{*}{$\mathrm{N}$} & \multicolumn{2}{|c|}{ Dung samples } & \multirow[b]{2}{*}{ signif. } \\
\hline & & $\%$ & range & signif. & & $\%$ & range & \\
\hline Poaceae & 7 & 93 & $86-100$ & & 6 & 86 & 59-100 & $6 \mathrm{H}$ \\
\hline Caryophyllaceae & 7 & 89 & $66-100$ & $1 \mathrm{H}$ & 8 & 32 & $7-45$ & $4 \mathrm{~L}$ \\
\hline Leguminosae & 3 & 23 & 7-49 & $3 \mathrm{~L}$ & 6 & 43 & $24-82$ & $1 \mathrm{H}$ \\
\hline Brassicaceae & 4 & 67 & $24-96$ & $1 \mathrm{~L}$ & 3 & 40 & $17-52$ & $1 \mathrm{~L}$ \\
\hline Compositae & 4 & 84 & $67-99$ & & 1 & 17 & 17 & $1 \mathrm{~L}$ \\
\hline Geraniaceae & 2 & 53 & $35-72$ & $1 \mathrm{~L}$ & 4 & 65 & $58-75$ & $1 \mathrm{H}$ \\
\hline Other & 10 & 85 & $43-100$ & $1 \mathrm{H} ; 1 \mathrm{~L}$ & 19 & 50 & $4-82$ & $1 \mathrm{H} ; 2 \mathrm{~L}$ \\
\hline
\end{tabular}

${ }^{1}$ A complete table including all species with their individual data and statistics, can be obtained from the author by request. 
(Baskin and Baskin 1989, Thompson, K. 1992), and the observed germinability could thus be even higher than that of normal soil samples. The relative importance of both trends is unknown, but the seed recharge of soil banks as the one studied may represent $>75 \%$ of the seed bank (Ortega et al. 1997), and the results presented here are thus relevant.

The first-year germinability of seeds in dung samples was $<50 \%$, in accordance with the survival to gut passage only of seeds protected from rapid water embedding. Although gut passage may accelerate germination (Russi et al. 1992b), it has been shown that only seeds with impervious coats do survive digestion (Gardener et al. 1993) leading in some occasions to a prevalence of slow-germinating seeds in dung (Simao et al. 1987). Other samples like those from deep or watterlogged soils may also contain large percentages of dormant seeds, as under such circumstances secondary dormancies arise in seeds (Baskin and Baskin 1989).

The main drawback to one-year germination tests derived from my analysis is the statement of significant differences in the accuracy of seed estimates among samples in one experiment and among experiments. As seed bank analysis are aimed at the knowledge of the viable seed content of samples but I have found differential germinabilities among them, data obtained after the first year of cultivation may be loaded with bias violating the basic principle of unbiased sampling (Thompson, S.K. 1992, Zar 1996). The magnitude of this problem can be of special concern whenever different sample types are used in any one analysis, specially so if some samples have been subjected to conditions favouring the presence of dormant seeds.

The differences in estimation accuracy among samples within experiments are less linked to pot overcrowding during cultivation than to the taxonomic affiliation of seeds in them. Thus, in each experiment I could identify some species with first-year germination percentages higher and lower than the rest, and they could be blamed for some of the detected biases. For instance, the higher germinability I found among the red deer dung samples with the most seeds was not associated to this fact, but to the coincidence in summer of the higher seed densities with the abundance of Cistus Ladanifer L. and Polypogon monspeliensis (L.) Desf. in dung, as both species showed a significantly high first-year germinability. Conversely, rabbit dung samples showed their seed content peak at the end of spring, coinciding with the maximum densities of some species in Caryophyllaceae. Among them, Sagina apetala Ard. stands out by the significatively low percentage of its seeds that germinated during the first growth cycle.

My analysis shows some patterns of biased germinability among plant families, but experiment-related differences persist in the taxonomic re-analysis of data. For instance, in both experiments I found grass species to be readilygerminable and the reverse behaviour for most legumes, a well-known pattern (Russi et al. 1992a). However, I re- corded relevant differences between experiments in species, like Biserrula pelecinus or species in the Caryophyllaceae, consistent with the alterations in the germination behaviour of seeds stated in experiments of herbivore gut passage (Russi et al. 1992b, Gardener et al. 1993). Biserrula pelecinus showed a significantly low germinability in soil samples $(14 \pm 5 \%)$ and high in those from dung (82 \pm $5 \%$ ), while the 7 most frequent species in Caryohyllaceae in soil samples had an $89 \%$ germinability in the first year, and only $32 \%$ the respective 8 species from dung samples. Differences in the taxonomic composition of samples will thus bias the results obtained after the first growth cycle, but experiment-related variability preclude an extrapolation of data based on known patterns of germinability among species or plant families.

In conclusion, I would suggest the cultivation of seed bank samples during at least two-growth cycles in order to attain a trustworthy estimation of their seed content, or to test the use of germination enhancement chemicals to ameliorate the problem, though the germination of many species is not accelerated by them either (Mass 1989). The workload of methods based on sorting and direct count of seeds, and the need to complement them with viability tests, still supports the use of germination methods when working with species-rich communities. However, the present analysis underlines the need to detect the fraction of seeds not germinating in the first growth-cycle in order to avoid important biases in the results, especially so if the study includes more than one type of sample, or samples that may contain a high fraction of dormant seeds.

Acknowledgements - Catherine Levassor and Francisco Suárez collaborated at different stages of the experimental work. This study has been partially funded by CICYT Projects AMB 96-1231 and AMB 99-0382.

\section{References}

Ball, D. A. and Miller, S. D. 1989. A comparison of techniques for estimation of arable soil seedbanks and their relationship to weed flora. - Weed Res. 29: 365-373.

Baskin, J. M. and Baskin, C. C. 1989. Physiology of dormancy and germination in relation to seed bank ecology. - In: Leck, M. A., Parker, V. T. and Simpson, R. L. (eds), Ecology of soil seed banks. Academic Press, pp. 53-66.

Bewley, J. D. and Black, M. 1994. Seeds. Physiology of development and germination. - Plenum Press.

Forcella, F. 1992. Prediction of weed seedling densities from buried seed reserves. - Weed Res. 32: 29-38.

Gardener, C. J., McIvor, J. G. and Jansen, A. 1993. Passage of legume seeds through the digestive tract of cattle and their survival in faeces. - J. Appl. Ecol. 30: 63-74.

Harper, J. L. 1977. Population biology of plants. - Academic Press.

Malo, J. E. and Suárez, F. 1995. Herbivorous mammals as seed dispersers in a Mediterranean dehesa. - Oecologia 104: 246 255. 
Malo, J. E., Jiménez, B. and Suárez, F. 1995. Seed bank build-up in small disturbances in a Mediterranean pasture: the contributiuon of endozoochorous dispersal by rabbits. -Ecography 18: 73-82.

Mass, D. 1989. Germination characteristics of some plant species from calcareous fens in southern Germany and their implications for the seed bank. - Holarct. Ecol. 12: 337-344.

Meyer, S. E. and Monsen, S. B. 1992. Big sagebush germination patterns: subspecies and population differences. - J. Range Manage. 45: 87-93.

Ortega, M., Levassor, C. and Peco, B. 1997. Seasonal dynamics of Mediterranean pasture seed banks along environemntal gradients. - J. Biogeogr. 24: 177-95.

Rice, W. R. 1989. Analyzing tables of statistical tests. - Evolution 43: 223-225.

Russi, L., Cocks, P. S. and Roberts, E. H. 1992a. Hard-seededness and seed bank dynamics of six pasture legumes. - Seed Sci. Res. 2: 231-241.
Russi, L., Cocks, P. S. and Roberts, E. H. 1992b. The fate of legume seeds eaten by sheep from a Merditerranean grassland. - J. Appl. Ecol. 29: 772-778.

Simao, M., Jones, R. M. and Ratcliff, D. 1987. Recovery of pasture seed ingested by ruminants. 1 . Seed of six tropical pasture species fed to cattle, sheep and goats. - Aust. J. Exp. Agricult. 27: 239-246.

Thanos, C. et al. 1992. Cistaceae: a plant family with hard seeds. - Isr. J. Bot. 41: 251-263.

Thompson, K. 1992. The functional ecology of seed banks. - In: Fenner, M. (ed.), Seeds. The ecology of regeneration in plant communities. CAB International. Oxon, U.K.

Thompson, S. K. 1992. Sampling. - Wiley.

Zar, J. H. 1996. Biostatistical analysis. 3rd ed. - Prentice-Hall. 